\title{
Effects of novel odor exposure on maternal aggression in mice
}

\author{
COLLEEN M. GARBE and ERNEST D. KEMBLE \\ University of Minnesota, Morris, Minnesota
}

\begin{abstract}
A variety of novel odors increase both risk assessment and defensive behaviors and inhibit offensive attack among male mice. In this experiment, the effects of a novel mammalian (wool) and nonmammalian (chocolate) odor on maternal aggression were examined. Both novel odors produced a mild suppression of lunge attacks. In addition, the chocolate odor reduced boxing behavior and the wool odor increased grooming. Neither odor altered other social behaviors. The results are consistent with previous data in suggesting that odor novelty evokes fear-motivated defensiveness and inhibits attack. These effects appear to be somewhat weaker than those seen among male mice, however.
\end{abstract}

The odors of a potential predator (cat) evoke a number of species-typical defensive behaviors in rats (e.g., stretched attention, flatback approach), which have been characterized as risk assessment (R. J. Blanchard \& D. C. Blanchard, 1987, 1990). Odor-induced risk assessment is ameliorated by benzodiazepine treatment (D. C. Blanchard, R. J. Blanchard, \& Rodgers, 1990; R. J. Blanchard, D. C. Blanchard, Weiss, \& Meyer, 1990) and is thought to reflect an underlying anxiety state that may be mediated by unconditioned recognition of predator odors (R. J. Blanchard \& D. C. Blanchard, 1990; Williams \& Scott, 1989). Such innate predator recognition has been suggested to occur among both mammals (e.g., Owings \& Coss, 1977) and birds (e.g., Smith, 1975, 1977). Subsequent research, however, suggests that novelty per se may be an important contributor to enhanced odor-induced defensiveness. A variety of novel nonpredator odors are avoided during preference/rejection tests (Kemble \& Gibson, 1992), induce hypoalgesia (Kemble \& Gibson, 1992; Lester \& Fanselow, 1985), and increase risk assessment behaviors (Garbe, Kemble, \& Rawleigh, in press). Finally, we (Kemble \& Garbe, 1993) have recently shown that both mammalian and nonmammalian novel odors reduce isolation-induced intermale attack in mice. Taken together, these data suggest that novel odors evoke rather substantial levels of fear that effectively inhibit attack behavior. In the present experiment, we explored the generality of such antiaggressive effects by examining the effects of two novel odors on maternal attack.

\section{METHOD}

\section{Subjects and Apparatus \\ The subjects were 27 experimentally naive female CD-1 mice (resi- dents) weighing $31.0-53.5 \mathrm{~g}$, and 27 males (intruders) weighing 28.6-41.1 g. After breeding, the females were singly housed in 12.5 $\times 17.0 \times 28.0 \mathrm{~cm}$ polypropylene cages. Male intruders were housed}

Please address reprint requests to E. Kemble, Division of Social Sciences, University of Minnesota-Morris, Morris, MN 56267. in groups of 8. All the mice were maintained under a 12:12-h light:dark cycle with ad-lib access to Purina Lab Chow and water. All testing was conducted during the light cycle. The females were randomly assigned to groups $(n s=9)$ designated to receive sheep wool, chocolate, or unsoiled sawdust bedding odorants during testing.

\section{Odorous Substances}

Novel odors were provided by $1.0 \mathrm{~g}$ of untreated sheep wool or $7.5 \mathrm{ml}$ of unsweetened powdered cocoa (Hershey's). Both novel odors effectively elevate risk assessment behaviors (Garbe et al., in press) and reduce intermale attack (Kemble \& Garbe, 1993). Unsoiled sawdust bedding $(36.0 \mathrm{ml})$ served as the control odor.

\section{Procedure}

All testing was conducted in the female resident's home cage 60-72 h after parturition. Females were habituated to placement under the videocamera for $15 \mathrm{~min}$ prior to testing. Food, water, and pups were removed $5 \mathrm{~min}$ prior to the test, and the designated odorous substance was then sprinkled evenly across the entire cage floor. After a 5-min exposure to the odorous substance, a male intruder weighing 2.4-12.4 g less than the female was introduced at the end of the cage most distal to the resident. The frequency and duration of offensive behaviors (lunge, kick, and chase), defensive behaviors (box, flee, and defensive upright), and sniffing and grooming were recorded for $15 \mathrm{~min}$ with a Panasonic AG-185 videocamera. Latency to the first attack was scored by stopwatch. Because several behaviors were totally absent in some of the groups, overall differences were analyzed by means of Kruskall-Wallis tests and pairwise comparisons by Mann-Whitney $U$ tests.

\section{RESULTS}

The mean frequency and duration of boxing by resident females is summarized in Figure 1 (upper panel). Overall analyses revealed significant novel-odor-induced differences in boxing duration $(H=6.07, p<.05)$, as well as marginally significant differences in frequency $(H=5.47, p<.10)$. Pairwise comparisons of boxing duration revealed that the chocolate group $(M=1.12 \mathrm{sec})$ boxed significantly less than either the wool group $(M=$ $5.02 \mathrm{sec}, p<.05)$ or the control group $(M=4.6 \mathrm{sec}$, $p<.05)$. The wool group, however, did not differ from the control group $(p>.10)$. The mean frequency and duration of lunge attacks are presented in the lower panel of Figure 1. Although there were marginally significant 


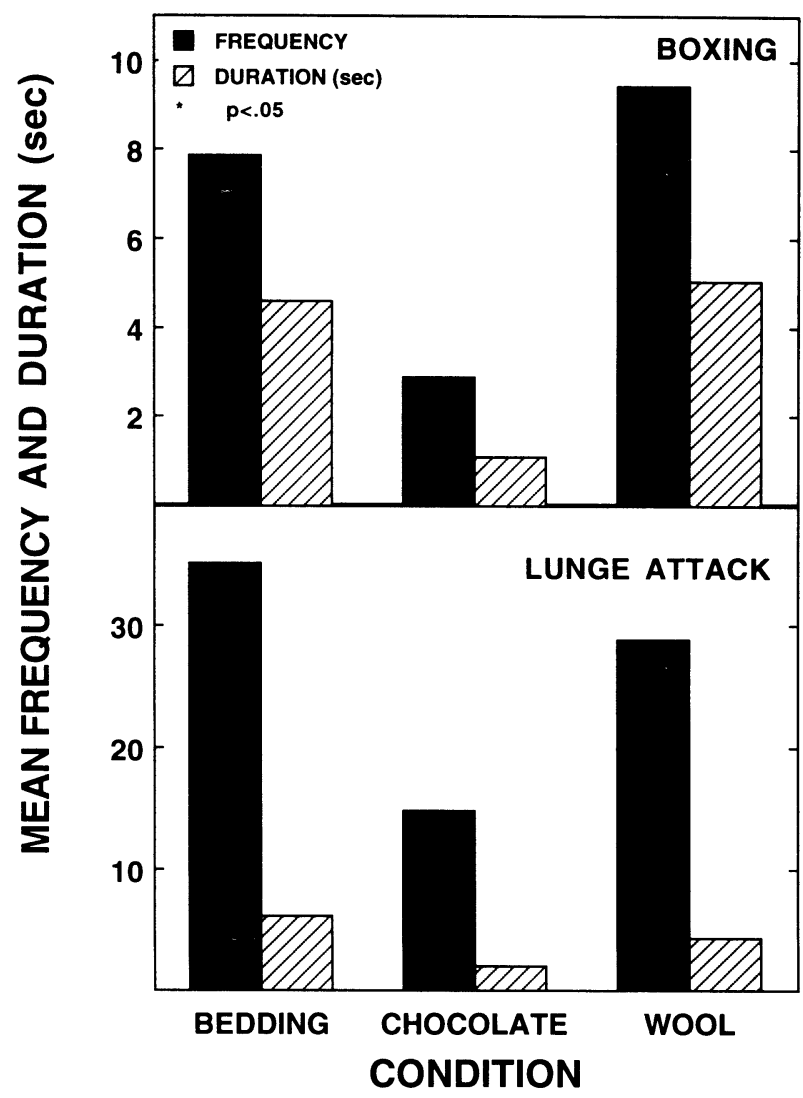

Figure 1. Mean frequency and duration of boxing (upper panel) and lunge attack (lower panel) by lactating females exposed to the odors of unsoiled bedding, chocolate, or wool. Differences are in comparison with the bedding group.

novel-odor-induced decreases in lunge-attack duration $(H=5.661, p<.10)$, there were no significant changes in their frequency $(p>.10)$. There were no significant differences in the duration of flight, defensive upright, or any other offensive measures including chase and kick and lunge-attack frequency (all $p s>.10$ ). In addition, there was no significant group difference in latency to first attack $(p>.10)$. Overall group analyses revealed significant novel-odor-induced changes in grooming frequency $(H=12.27, p<.005)$ and duration $(H=27$, $p<.05)$. Pairwise comparisons of grooming frequency revealed significant increases in grooming in the wool group $(M=30.44)$ when compared with both the bedding $(M=13.44, p<.005)$ and chocolate $(M=13.56$, $p<.005)$ groups. Similar increases in grooming duration were evident between the wool $(M=150.47 \mathrm{sec})$ and chocolate $(M=56.65 \mathrm{sec}, p<.005)$ groups. The chocolate group did not differ from the bedding group, however $(p>.10)$. There were no significant group differences in any of the sniffing behaviors either individually or when pooled $(p s>.10)$.

\section{DISCUSSION}

The results of this experiment were generally consistent with our earlier findings of odor-induced hyperdefensiveness (Garbe et al., in press) and decreased aggression (Kemble \& Garbe, 1993) among male mice. Taken together, these data provide evidence that novel odors elevate defensiveness toward either predators or litter-threatening male conspecifics. Furthermore, the mammalian odor of wool and chocolate seemed to be roughly equivalent in their behavioral effects. This finding fails to support an earlier suggestion that mammalian odors may be uniquely effective fear stimuli (Garbe et al., in press). It must be noted, however, that the novel odors in this experiment did not reliably alter a number of major offensive or defensive behaviors and, for reasons that remain unclear, wool increased grooming behavior. Because female attack differs from that of males in the postures employed (e.g., Erskine, Barfield, \& Goldman, 1978; Flannelly, Flannelly, \& R. J. Blanchard, 1984; Gandelman, 1972) and in favored attack targets (e.g., Svare \& Gandelman, 1973), the weaker pattern of effects among females may reflect a sex difference in the mechanisms underlying the two forms of attack. Maternal attack is commonly thought to be motivated by protection of the young (e.g., Svare, 1983), so it may be more adaptive for females to attack while intruding males are still at some distance and present less salient olfactory stimulation. Indeed, rapid lunge attacks followed by retreat are common among females, but not males (e.g., Erskine et al., 1978). Furthermore, social investigatory behavior (mainly sniffing), which is nearly always a prelude to intermale attack (e.g., Svare, 1983), is characteristically absent during maternal attack (e.g., Gandelman, 1972). Nevertheless, these data suggest that olfactory processes contribute, although modestly, to the mediation of maternal attack.

\section{REFERENCES}

Blanchard, D. C., Blanchard, R. J., \& Rodgers, R. J. (1990). Pharmacological and neural control of anti-predator defense in the rat. $\mathrm{Ag}$ gressive Behavior, 16, 165-175.

BlanChaRd, R. J., \& BlanchaRd, D. C. (1987). An ethoexperimental approach to the study of fear. The Psychological Record, 37 , 305-316.

Blanchard, R. J., \& BlanchaRd, D. C. (1990). An ethoexperimental analysis of defense, fear, and anxiety. In N. McNaughton \& G. Andrews (Eds.), Anxiety (pp. 124-133). Dunedin: University of Otago Press.

Blanchard, R. J., Blanchard, D. C., Weiss, S. M., \& MeYer, S. (1990). The effects of ethanol and diazepam on reactions to predatory odors. Pharmacology, Biochemistry \& Behavior, 35, 775-780.

ERSKINE, M. S., BARFIELD, R. J., \& GoldMAN, R. (1978). Intraspecific fighting during late pregnancy and lactation in rats and effects of litter removal. Behavioral Biology, 23, 206-218.

Flannelly, K. J., Flannelly, L., \& Blanchard R. J. (1984). Adult experience and the expression of aggression: A comparative analysis. In K. J. Flannelly, R. J. Blanchard, \& D. C. Blanchard (Eds.), Biological perspectives on aggression (pp. 207-259). New York: Alan R. Liss.

Gandelman, R. (1972). Postpartum aggression elicited by the presence of an intruder. Hormones \& Behavior, 3, 23-28.

Garbe, C. M., Kemble, E. D., \& RaWleigh, J. M. (in press). Novel odors evoke risk assessment and suppress appetitive behaviors in mice. Aggressive Behavior.

Kemble, E. D., \& GARBE, C. M. (1993). Effects of novel odors on intermale aggression in mice. Manuscript in preparation.

Kemble, E. D., \& Gibson, B. M. (1992). Avoidance and hypoalgesia induced by novel odors in mice. Psychological Record, 42, 555-563.

LeSTer, L. S., \& FANSElow, M. A. (1985). Exposure to a cat produces opioid analgesia in rats. Behavioral Neuroscience, 99, 756-759.

OwINGs, D. H., \& Coss, R. G. (1977). Snake mobbing by California ground squirrels: Adaptive variation and ontogeny. Behaviour, 62, 50-69. 
SмIтH, S. M. (1975). Innate recognition of a coral snake pattern by a possible avian predator. Science, 187, 759-760.

SMIтH, S. M. (1977). Coral-snake pattern recognition and stimulus generalisation by naive great kiskadees (Aves: Tyrannidae). Nature, $\mathbf{2 6 5}$ 535-536.

Svare, B. (1983). Psychobiological determinants of maternal aggressive behavior. In E. C. Simmel, M. E. Hahn, \& J. K. Walters (Eds.), Aggressive behavior: Genetic and neural approaches (pp. 129-146). Hillsdale, NJ: Erlbaum.
Svare, B., \& Gandelman, R. (1973). Postpartum aggression in mice: Experiential and environmental factors. Hormones \& Behavior, 4, 323-334.

Williams, J. L., \& Scott, D. K. (1989). Influence of conspecific and predatory stressors and their associated odors on defensive burying and freezing responses. Animal Learning \& Behavior, 17, 383-393.

(Manuscript received June 23, 1993.) 